\title{
Robot Reliability and Safety
}




\section{B.S. Dhillon}

\section{Robot Reliability and Safety}

With 35 Illustrations

Springer-Verlag

New York Berlin Heidelberg London Paris

Tokyo Hong Kong Barcelona Budapest 
B.S. Dhillon

Engineering Management Programme

Faculty of Engineering

University of Ottawa

Ottawa, Ontario

Canada K1N 6N5

Printed on acid-free paper.

(C) 1991 Springer-Verlag New York, Inc.

Softcover reprint of the hardcover 1st edition 1991

All rights reserved. This work may not be translated or copied in whole or in part without the written permission of the publisher (Springer-Verlag New York, Inc., 175 Fifth Avenue, New York, NY 10010, USA), except for brief excerpts in connection with reviews or scholarly analysis. Use in connection with any form of information storage and retrieval, electronic adaptation, computer software, or by similar or dissimilar methodology now known or hereafter developed is forbidden.

The use of general descriptive names, trade names, trademarks, etc., in this publication, even if the former are not especially identified, is not to be taken as a sign that such names, as understood by the Trade Marks and Merchandise Marks Act, may accordingly be used freely by anyone.

Typeset by Asco Trade Typesetting Ltd., Hong Kong.

\section{1}


This book is affectionately dedicated to my son Mark 


\section{Preface}

Robots are increasingly being used in industry to perform various types of tasks. Some of the tasks performed by robots in industry are spot welding, materials handling, arc welding, and routing. The population of robots is growing at a significant rate in various parts of the world; for example, in 1984, a report published by the British Robot Association indicated a robot population distribution between Japan $(64,600)$, Western Europe $(20,500)$, and the United States $(13,000)$. This shows a significant number of robots in use. Data available for West Germany and the United Kingdom indicate that in 1977 there were 541 and 80 robots in use, respectively, and in 1984 these numbers went up to 6600 and 2623, respectively. Just as for other engineering products, the reliability and safety of robots are important.

A robot has to be safe and reliable. An unreliable robot may become the cause of unsafe conditions, high maintenance costs, inconvenience, etc. Robots make use of electrical, mechanical, pneumatic, electronic, and hydraulic parts. This makes their reliability problem a challenging task because of the many different sources of failures. According to some published literature, the best mean time between failures (MTBF) achieved by robots is only 2500 hours. This means there is definite room for further improvement in robot reliability. With respect to safety, there have been five fatal accidents involving robots since 1978. A Swedish report stated that in Sweden there were 36 accidents involving robots that caused human injury during the period 1979 to 1983. Furthermore, Japanese findings indicate that $8 \%$ of persons working with robots have been injured, and as many as $36 \%$ of them have experienced an accident of some sort. Because of such situations, the robot safety issue has become of the utmost importance. Hence, one may say that robot reliability and safety are the most challenging problems to be dealt with, and this book focuses on both of these important areas.

The main objective of this book is to be wide in scope, in particular with respect to reliability. However, some areas of reliability, such as software reliability and fault tolerance, are not covered in depth due to several factors: space limitation, the size of computer software and hardware in robots in relation to general computer systems, etc. Some general concepts presented in 
Chapter 2 can be applied in the case of fault tolerance. For example, triplemodular redundancy (TMR) is probably the most discussed term in computer redundancy reliability, and is basically a special case of the $k$-out-of- $n$ system with a voter. The $k$-out-of- $n$ system is described in Chapter 2 . In any case, for further studies of computer software and hardware reliability and other areas, the relevant references are cited at appropriate places in the text.

This book is the result of filtering through almost all of the published literature on robot reliability and safety, as is evident from the listed references in the book. The book is intended for readers such as practicing engineers and senior undergraduate and graduate students with no previous knowledge of the subject. In general, emphasis is on the structure of concepts rather than on mathematical rigor and minute detail. The sources of most of the material presented are given in the references, if the reader wishes to delve deeper into a specific area. The book contains over 750 references and approximately 40 solved examples. The references will provide the reader with further information on relevant topics.

Twelve chapters and an appendix constitute Robot Reliability and Safety. The purpose of Chapters 1 to 3 is to provide the necessary background to help in understanding the remaining chapters of the book. Chapter 1 briefly discusses robots and robot reliability and safety histories, basic terms and definitions, and the scope of the book. Introductory aspects of general reliability and safety are presented in Chapter 2. Chapter 3 consists of basic robotics; this allows the reader to familiarize himself/herself with the subject of robotics, or if he/she already possesses such a background on the said topic, to refresh his/her memory. The topic of robot accidents is discussed in detail in Chapter 4. This chapter covers subjects such as real-life examples of robot accidents in Japan, Western Europe, and the United States; causes and characteristics of robot accidents, effects of robot accidents, and robot accident analysis and prevention. Chapter 5 discusses various fundamental aspects of robot safety: Some of these are robot safety problems; the use of robots to promote safety; weak points in planning, design, and operations causing safety problems; the manufacturer's and user's role in robot safety; and robot safeguard methods. Several topics related to robot safety are discussed in Chapter 6: These include robot safety education, safety considerations in robot testing and start-up, commissioning and acceptance, safety considerations in robot welding operations, robot safety in the automobile industry, robot safety standards, and robot safety research.

Chapter 7 covers human factors in robotics. Human factors play an important role regarding robot reliability and safety. Topics such as robots versus humans, human factors' issues during the factory integration of robot systems, benefits and drawbacks of robotization from the standpoint of human factors, guidelines for safeguarding the operator and the teacher, human error data in robotics, and the mathematical modeling of robots with respect to human error are described. A mathematical model presented in this chapter is applicable when the robot system failure times due to humans or nonhumans are 
exponentially distributed. If different human error rates occur during robot teaching, operation, and design, one should take an average of these three rates and then use the resulting figure in the derived model equations. However, if distinct probabilities are required for each of these three distinct modes, then the new equations can be developed in a similar manner.

The subject of robot reliability is discussed in depth in Chapter 8. Many reliability-related topics are covered in this chapter: robot-related failure terms, general categories of robot failures and their protection, selected references related to robot reliability, types of robot halts and warm restarts, hazard detector's fail-safe design, guidelines for developing a robot reliability standard, robot reliability measures, and a reliability analysis of electric and hydraulic robots with the aid of block diagram and fault tree methods. Chapter 9 discusses the important subject of robot maintenance; this subject is related to robot reliability, because poor maintenance leads to poor reliability. Failure data and analysis are discussed in Chapter 10, and are vital for robot-reliability analyses. This chapter covers many topics, some of which are reliability-related data sources, failure data for selected items and tasks, and the hazard plotting method. Economics generally plays an important role in robot reliability and safety analyses; therefore, Chapter 11 is totally devoted to this theme and discusses various aspects of robot economics. The topics covered are concerned with factors for installing robots, robot installation costs, robot economic techniques and methods for making robot financial decisions, robot life-cycle costing, and robot associated-cost estimation models. Robot testing is very important in the reliability evaluation of robots under development; thus, Chapter 12 discusses robot testing and the pertinent information related to robots. Some of the topics covered in this chapter are robot performance testing, robot reliability testing, robot specifications, and general information on robots. The appendix lists over 460 references on robot reliability and safety and related areas.

The author wishes to thank the editorial department at Springer-Verlag New York, Inc., for their close interest in this project. The author is indebted to his relatives, students, and friends for their interest, help, and encouragement in moments of need. Last, but not least, I thank my wife, Rosy, for typing the original manuscript and for her help in proofreading. During the preparation of the manuscript, her patience and tolerance were also appreciated. 


\section{Contents}

Preface

\section{CHAPTER 1}

Introduction 1

1.1. History of Robots 1

1.2. Brief History of Robot Reliability and Safety 2

1.3. Terms and Definitions 3

1.4. Scope of the Book 4

Summary 4

Problems $\quad 4$

References $\quad 5$

\section{CHAPTER 2}

Introduction to Reliability and Safety $\quad 6$

$\begin{array}{ll}\text { 2.1. Introduction } & 6\end{array}$

2.2. Reliability and Safety-Related Terms and Definitions 7

2.3. Organizations Concerned with Reliability or Safety, or Both 8

2.4. Reliability and Safety Periodicals and Conferences 9

2.5. Reliability and Safety-Related Data Sources 10

2.6. Selective Texts on Reliability and Safety 11

2.7. Reliability 12

2.8. Safety 26

Summary $\quad 30$

$\begin{array}{ll}\text { Problems } & 31\end{array}$

$\begin{array}{ll}\text { References } & 32\end{array}$

\section{CHAPTER 3}

Introduction to Robotics $\quad 34$

3.1. Introduction 34

3.2. Some Attributes of Robots Available Commercially, Major Users of Industrial Robots in Japan, and the United States' Robot Estimates by Application $\quad 35$

3.3. Robotics Research and Robot Application Areas 35

3.4. Advantages of and Motivations for Using Robots, and Arguments Against Robots 
3.5. Comparisons of Humans with Machines, Generations of Robots, and Robot Qualities Being Sought by Roboticists

3.6. Areas of Commonly Asked Questions by Potential Robot Users, Factors for Using Robots Instead of Humans, and Rules and Procedures for Introducing Robots

3.7. Robot Classifications, Production Robots, and Robot Structure Categories

3.8. Robot Mechanical Design Decisions and Useful Guidelines, and Important Physical and Operational Characteristics Vital for Robot Selection and Design

3.9. Robot Public Relation Guidelines

Summary

Problems

References

CHAPTER 4

Robot Accidents

4.1. Introduction 49

4.2. Real-Life Examples of Robot Accidents 49

4.3. Robot Accidents in Japan, Western Europe, and the United States 51

4.4. Causes and Characteristics of Robot Accidents 55

4.5. Effects of Robot Accidents and Periods Off Work Due to Robot Accidents

4.6. Robot Accidents at Manufacturer and User Sites $\quad 59$

4.7. Robot Accident Analysis and Prevention 60

$\begin{array}{ll}\text { Summary } & 65\end{array}$

Problems $\quad 66$

$\begin{array}{ll}\text { References } & 66\end{array}$

\section{CHAPTER 5}

Fundamentals of Robot Safety $\quad 69$

$\begin{array}{ll}\text { 5.1. Introduction } & 69\end{array}$

5.2. Robotic Safety Problems and Hazards, and the Use of
Robots to Promote Safety

5.3. Weak Points in Planning and Design, and Operations Causing $\begin{array}{ll}\text { Safety Problems } & 73\end{array}$

5.4. The Manufacturer's and User's Role in Robot Safety 74

5.5. Safety Considerations in Robot Design, Installation, $\begin{array}{ll}\text { Programming, and Operation and Maintenance } & 76\end{array}$

$\begin{array}{ll}\text { 5.6. Robot Safeguard Methods } & 78\end{array}$

$\begin{array}{lr}\text { Summary } & 82\end{array}$

$\begin{array}{lr}\text { Problems } & 83\end{array}$

$\begin{array}{ll}\text { References } & 83\end{array}$

\section{CHAPTER 6}

Topics in Robot Safety 85

$\begin{array}{ll}\text { 6.1. Introduction } & 85\end{array}$

6.2. Robot Safety Education $\quad 85$ 
6.3. Safety Considerations in Robot Testing and Start-Up,

Commissioning, and Acceptance

6.4. Safety Considerations in Robot Welding Operations

6.5. Robot Safety in the Automobile Industry

6.6. Stopping Grippers of Industrial Robots Not Dropping/Throwing Work Items When Experiencing Energy Loss or Not Gripping on the Return of Energy

6.7. Robot Standardization and Safety Standards 95

6.8. Robot Safety Research 97

Summary $\quad 98$

Problems $\quad 98$

$\begin{array}{ll}\text { References } & 99\end{array}$

\section{CHAPTER 7}

Human Factors in Robotics $\quad 101$

$\begin{array}{ll}\text { 7.1. Introduction } & 101\end{array}$

7.2. Robots Versus Humans 101

7.3. Human Factors' Issues During the Factory Integration of Robotic Systems

7.4. Built-In Human Biases and Some Design Improvement Guidelines for Improving Robot Operator Comfort and Productivity

7.5. Benefits and Drawbacks of Robotization from the Standpoint of Human Factors and Rules of Robotics with Respect to Humans

7.6. Humans at Risk from Robots and Guidelines for Safeguarding the Operator and the Teacher

7.7. Human Factors' Considerations to Robotic Safety

7.8. Training for Reducing Human Error in Robotics and Human Error Data in Robotics

7.9. Reliability Analysis of a Robot System with Human Error

Summary

Problems

References

\section{CHAPTER 8}

Robot Reliability

8.1. Introduction

8.2. Robot-Related Failure Terms, Robot Failures, and

Literature on Robot Reliability

8.3. General Categories of Robot Failure and Their Protection

8.4. Types of Robot Halts and Warm Restarts

8.5. Robot Effectiveness and Hazard Detectors Fail-Safe Design

8.6. Robot Reliability Surveys and Guidelines for Developing a Robot Reliability Standard

8.7. Robot Reliability Measures

8.8. Reliability Analyses of Electric and Hydraulic Robots 134

Summary

Problems

References 
CHAPTER 9

Robot Maintenance

9.1. Introduction

9.2. General Maintenance Functions and Types of Maintenance 150

9.3. Robot Maintenance Needs and Types 151

9.4. Robot Parts and Special Tools for Maintenance and Repair 152

9.5. Robot Warranty Coverage and Preventive Maintenance Kits 153

9.6. Robot Inspection 154

9.7. Some Guidelines for Safeguarding Robot Maintenance Personnel 157

9.8. Some Models Useful in Performing Robot Maintenance 158

Summary 166

$\begin{array}{ll}\text { Problems } & 167\end{array}$

$\begin{array}{ll}\text { References } & 167\end{array}$

CHAPTER 10

Failure Data and Analysis $\quad 169$

$\begin{array}{ll}\text { 10.1. Introduction } & 169\end{array}$

10.2. Uses of Failure Data with Respect to Robots 169

10.3. Failure Reporting and Documentation System for Robots 170

10.4. Reliability Data Sources 170

10.5. An Approach for Establishing an Event Data Bank, the Failure Report Form, and Major Difficulties Associated with Failure Recording $\quad 172$

$\begin{array}{ll}\text { 10.6. Robot Inspection and Repair Records } & 173\end{array}$

10.7. Documents, Banks, and Organizations for Obtaining Failure Data for Robot Reliability Studies

10.8. Failure Data for Selected Items and Tasks $\quad 174$

10.9. Hazard Plotting Method 184

$\begin{array}{lr}\text { Summary } & 189\end{array}$

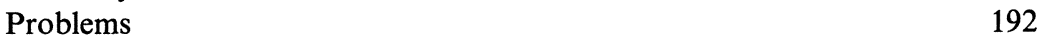

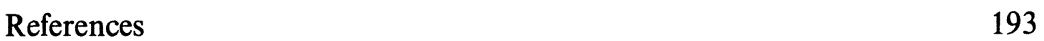

CHAPTER 11

Robot Economics $\quad 195$

$\begin{array}{ll}\text { 11.1. Introduction } & 195\end{array}$

11.2. Factors for Installing Robots and Advantages of Robotization 195

11.3. Cost of Installing Robots and Their Economic Benefits 196

11.4. Basic Robot Economic Techniques 197

11.5. Methods for Making Robot Financial Decisions 202

11.6. Robot Life Cycle Costing 204

11.7. Robot Associated Cost Estimation Models 205

$\begin{array}{ll}\text { Summary } & 208\end{array}$

Problems 208

$\begin{array}{ll}\text { References } & 209\end{array}$

CHAPTER 12

Robot Testing and Information Related to Robots 210

$\begin{array}{ll}\text { 12.1. Introduction } & 210 \\ & \end{array}$

12.2. Robot Performance Testing 210 
12.3. Robot Reliability Testing

12.4. Selective Mathematical Models 218

12.5. Robot Specifications 220

12.6. General Information on Robots 221

Summary $\quad 222$

Problems $\quad 222$

References $\quad 225$

APPENDIX

Bibliography of Literature on Robot Reliability and Safety and on Related Areas

$\begin{array}{ll}\text { A.1. Introduction } & 226\end{array}$

A.2. Robot Reliability and Safety $\quad 226$

A.3. Robot Maintenance 244

A.4. Robot Economics 246

$\begin{array}{ll}\text { A.5. Miscellaneous } & 248\end{array}$

$\begin{array}{ll}\text { Index } & 251\end{array}$ 